\title{
Chronic Maternal Fluoxetine Infusion in Pregnant Sheep: Effects on the Maternal and Fetal Hypothalamic-Pituitary-Adrenal Axes
}

\author{
JANNA L. MORRISON, K. WAYNE RIGGS, CALY CHIEN, NANCY GRUBER, \\ I. CAROLINE MCMILLEN, DAN W. RURAK
}

\begin{abstract}
Department of Obstetrics and Gynaecology, British Columbia Research Institute for Children's \& Women's Health, Vancouver, British Columbia, Canada V5Z 4H4 [J.L.M., N.G., D.W.R.], Faculty of Pharmaceutical Sciences, University of British Columbia, Vancouver, British Columbia, Canada V6T $1 Z 3$ [K.W.R., C.C.], and Department of Physiology, Adelaide University, Adelaide, South Australia, Australia 5005 [I.C.M.]
\end{abstract}

\begin{abstract}
Depression during pregnancy is frequently treated with the selective serotonin reuptake inhibitor, fluoxetine (FX). FX increases serotonergic neurotransmission and serotonin plays a role in the regulation of the hypothalamic-pituitary-adrenal (HPA) axis. We have therefore investigated the effect of chronic administration of FX to the pregnant ewe on the maternal and fetal HPA axes. Nineteen late-gestation sheep were surgically prepared for chronic study of the fetus. FX $(n=7,98.5 \mu \mathrm{g} / \mathrm{kg} / \mathrm{d})$ or sterile water (control, $n=8$ ) was administered to the ewe for $8 \mathrm{~d}$ by constant rate i.v. infusion with an initial FX bolus dose of 70 mg. Maternal and fetal plasma ACTH and cortisol concentrations were determined at $0700 \mathrm{~h}$ each day. Maternal plasma ACTH concentrations fell on infusion $\mathrm{d} 2$, but no changes were observed in maternal plasma cortisol concentrations. Fetal plasma ACTH concentrations increased on infusion $\mathrm{d} 7$, and fetal plasma cortisol concentrations increased on infusion $\mathrm{d} 6,7$, and 8 in the FX group. In addition, the regression coefficient for the relationship
\end{abstract}

\section{ABSTRACT}

between fetal ACTH and cortisol levels was significantly greater in the FX group compared with the control group. Thus, maternal FX treatment increased fetal plasma cortisol concentration. These results are of particular interest in the context that exposure of the fetus to excess glucocorticoids at critical windows during development has been shown to increase the risk of poor health outcomes in later life. (Pediatr Res 56: 40-46, 2004)

$\quad$ Abbreviations
SSRI, selective serotonin reuptake inhibitor
FX, fluoxetine
HPA, hypothalamic-pituitary-adrenal
ACTH, adrenocorticotrophin
NFX, norfluoxetine
CRH, corticotrophin-releasing hormone
AVP, arginine vasopressin

Clinical depression occurs in 5-15\% of pregnant women (1). Treatment of depression during pregnancy is important to fetal outcome by preventing poor maternal self-care and nutrition, disturbed sleep, lack of prenatal care, increased exposure to alcohol and drugs, and a higher risk of suicide by the mother (1). Depression at $28 \mathrm{wk}$ gestation is related to an increase in negative pregnancy outcome, including an increased risk of low-birth-weight newborns, preterm delivery, and small-for-

Received July 10, 2003; accepted November 11, 2003.

Correspondence: Janna Morrison, Ph.D., Medical School South, Rm. S515, Discipline of Physiology, School of Molecular and Biomedical Sciences, Adelaide University, Adelaide, SA, Australia, 5005; e-mail: janna.morrison@adelaide.edu.au

Supported by a grant from the Canadian Institutes of Health Research (CIHR). D.W.R. is the recipient of an investigatorship award from the British Columbia Research Institute for Children's \& Women's Health. J.L.M. is the recipient of a CIHR Studentship. C.C. is the recipient of a PMAC/HRF-CIHR studentship. Novopharm Ltd., Toronto, ON, Canada, generously donated the fluoxetine hydrochloride used in these studies.

DOI: 10.1203/01.PDR.0000128981.38670.28 gestational-age newborns (2). FX is a SSRI that increases serotonergic neurotransmission and is prescribed clinically for the treatment of depression, obsessive-compulsive disorder, and bulimia (3). It and other SSRIs have become increasingly used for the treatment of depression in pregnancy because of their effectiveness and lower incidence of maternal side effects and wider safety margin compared with tricyclic antidepressants and monoamine oxidase inhibitors $(4,5)$. However, there have been several reports that use of these drugs during pregnancy can increase the incidence of adverse pregnancy outcomes, including preterm delivery, fetal growth restriction, and poor neonatal adaptation (5-8). There is also evidence for postnatal consequences of prenatal SSRI exposure, including reduced weight gain, slight delays in psychomotor development and motor movement control, and our own findings of reduced facial and heart rate responses to painful stimuli $(9-11)$. 
FX and other SSRIs increase extracellular serotonin (5-HT) levels acutely and serotonergic neurotransmission chronically, and these actions could underlie the reported adverse effects of these agents on pregnancy outcome and postnatal development $(7,10,12)$. Serotonin plays a major role in the regulation of the HPA axis and adrenocortical secretion of cortisol (13). The actions of serotonin, released by neurons originating in the midbrain raphe nucleus, are mediated by $5-\mathrm{HT}_{1 \mathrm{~A}}$ and $5-\mathrm{HT}_{2 \mathrm{~A} / 2 \mathrm{C}}$ receptors in the paraventricular nucleus of the hypothalamus (14-17).

Basal ACTH and cortisol plasma concentrations did not change in humans receiving $20 \mathrm{mg}$ FX for $20 \mathrm{~d}$ (18). Most studies of chronic FX treatment, however, have focused on the neuroendocrine responses to a challenge of the serotonergic system with either 5-hydroxytryptophan (5-HTP), the precursor to $5-\mathrm{HT}$, or a $5-\mathrm{HT}_{1 \mathrm{~A}}$ agonist. Compared with controls, an attenuated $\mathrm{ACTH}$ and cortisol/corticosterone response to $5-\mathrm{HT}_{1 \mathrm{~A}}$ activation occurred after chronic $\mathrm{FX}$ treatment in humans $(18,19)$ and rats $(20-22)$. Rats treated with $10 \mathrm{mg} / \mathrm{kg}$ FX for $21 \mathrm{~d}$ exhibited attenuated ACTH and cortisol responses to a $5-\mathrm{HT}_{1 \mathrm{~A}}$ agonist (8-OH-DPAT) (21). The FX-elicited blunting of $\mathrm{ACTH}$ and cortisol responses to $5-\mathrm{HT}_{1 \mathrm{~A}}$ receptor stimulation appears to involve desensitization of postsynaptic 5-HT $\mathrm{HA}_{1 \mathrm{~A}}$ receptors (19), whereas the antidepressant actions of $\mathrm{FX}$ involve desensitization of presynaptic $5-\mathrm{HT}_{1 \mathrm{~A}}$ autoreceptors (3). Taken together, these studies illustrate that our current knowledge of the effects of FX on the endocrine system without serotoninergic challenge is incomplete. Furthermore, no studies have investigated the impact of maternal FX treatment on the fetal endocrine system.

Placental transfer of FX has been demonstrated in the rat (23), human (24), and sheep (25). In adults, FX is metabolized to norfluoxetine (NFX), which also has antidepressant activity; however, in pregnant sheep, NFX has not been detected in the fetus after fetal drug administration, suggesting that FX is not metabolized in the fetus $(24,26)$. FX may, however, have similar effects in the fetus as in the adult on serotonin neurotransmission and HPA axis function. However, only one study has investigated the interaction between serotonin and the fetal HPA axis. Intravenous infusion of 5-HTP to the sheep fetus at 110 and $130 \mathrm{~d}$ gestation increased serotonin in hypothalamic tissue (27). Thus, our hypothesis is that maternal FX treatment in sheep will increase fetal HPA axis function as measured by an increase in fetal plasma $\mathrm{ACTH}$ and cortisol concentration.

\section{MATERIALS AND METHODS}

Animals and surgical preparation. Nineteen time-bred Dorset/Suffolk cross, pregnant sheep were surgically prepared between 118 and $122 \mathrm{~d}$ gestation (term, $147 \mathrm{~d}$ ). All experimental protocols and procedures performed on the sheep conformed to the guidelines of the Canadian Council on Animal Care and were approved by The University of British Columbia Animal Care Committee. Surgical procedures have been described in detail previously (28). Briefly, anesthesia was induced with $1 \mathrm{~g}$ pentothal and maintained with $1.5 \%$ isoflurane after intubation. A midline incision in the maternal abdomen allowed access to the uterus to expose the fetus for implantation of polyvinyl catheters (Tygon, Akron, OH, U.S.A.) in the trachea, femoral arteries, lateral tarsal vein, and amniotic cavity. As previously reported $(12,29)$, animals were instrumented for measurement of fetal behavioral state and uterine artery blood flow.

Experimental protocol. Ewes were housed in a 12:12 light/ dark cycle (lights on at $0600 \mathrm{~h}$ ) with grain and hay once daily between 0830 and $0900 \mathrm{~h}$ and additional hay between 1530 and $1600 \mathrm{~h}$. Ewes recovered for 3-4 d after surgery before experiments began. A preinfusion day preceded an 8-d infusion of either sterile water $(n=8)$ or FX $(n=7)$. The control group consisted of six female and two male fetuses, whereas the FX group consisted of three female and four male fetuses. There were one singleton, six twins, and one set of triplets in the control group and three singletons and four twins in the FX group. At $0700 \mathrm{~h}$ on infusion d 1, a 10-mL bolus injection of either $70 \mathrm{mg} \mathrm{FX}$ or sterile water was given over $2 \mathrm{~min}$ into the maternal femoral vein catheter followed by continuous infusion of $98.5 \mu \mathrm{g} / \mathrm{kg} / \mathrm{d} \mathrm{FX}$ or an equivalent volume of sterile water for $8 \mathrm{~d}$. The loading dose and infusion rate were calculated based on volume of distribution and systemic clearance data obtained from FX i.v. bolus pharmacokinetic studies in pregnant sheep previously performed in our laboratory (25). At $0700 \mathrm{~h}$ each day, maternal and fetal blood samples were collected for analysis of blood gases $(1 \mathrm{~mL})$ and plasma concentration of FX, cortisol, and ACTH $(1.5 \mathrm{~mL})$ and stored at $-20^{\circ} \mathrm{C}$ for $2 \mathrm{wk}$ and then at $-80^{\circ} \mathrm{C}$. To limit total blood volume removed, not all hormones were measured in all animals at all time points. All fetuses delivered spontaneously (12).

Blood gas analysis. Blood samples were analysed for $\mathrm{pH}$, $\mathrm{PCO}_{2}$ and $\mathrm{PO}_{2}$ with an IL $1306 \mathrm{pH} /$ blood gas analyser (Allied Instrumentation Laboratory, Milan, Italy) and temperature corrected to $39.5^{\circ} \mathrm{C}$ for fetal samples and $39^{\circ} \mathrm{C}$ for maternal samples. $\mathrm{Hb}$ and oxygen saturation were measured with an OSM-2 Hemoximeter (Radiometer, Copenhagen, Denmark).

Fluoxetine analysis. A rapid, sensitive, and selective chiral assay for FX and NFX enantiomers using gas chromatography mass spectrometry with selective ion monitoring developed in our laboratory was used for plasma FX analysis as previously described (25). Samples were analyzed for plasma FX and NFX concentrations only if maternal and fetal blood samples were collected at all time points in the protocols from $0700 \mathrm{~h}$ on the preinfusion day to $72 \mathrm{~h}$ postinfusion $(n=6)$.

ACTH hormone RIA. Plasma concentrations of immunoreactive ACTH were determined using an ${ }^{125}$ I RIA kit (ICN Biomedicals, Seven Hills, NSW, Australia). The intra-assay coefficient of variation was $<10 \%$ and the interassay coefficient of variation was $14.6 \%$. The rabbit antihuman $\mathrm{ACTH}^{1 \rightarrow 39}$ had a cross reactivity of $<0.01 \%$ with $\alpha$-melanocytestimulating hormone, $\beta$-endorphin, $\alpha$-lipotropin, and $\beta$-lipotropin. The sensitivity of the assay was $7 \mathrm{pg} / \mathrm{mL}$ (30).

Cortisol RIA. Total cortisol plasma concentration determination was performed using an ${ }^{125}$ I RIA kit (Orion Diagnostica, Espo, Finland). The average efficiency of recovery of ${ }^{125} \mathrm{I}$ cortisol using dichloromethane extraction was $90 \%$ (31). The sensitivity of the assay was $0.39 \mathrm{nmol} / \mathrm{L}$. The rabbit anticortisol antibody cross-reacted $<1 \%$ with cortisone and 17-hy- 
Table 1. Maternal and fetal plasma FX concentrations $(\mathrm{n}=6)$ at 0700 h daily

\begin{tabular}{lcc}
\hline & Maternal FX $(\mathrm{ng} / \mathrm{mL})$ & Fetal FX $(\mathrm{ng} / \mathrm{mL})$ \\
\hline Preinf & $0.0 \pm 0.0$ & $0.0 \pm 0.0$ \\
Inf 1 & $0.0 \pm 0.0$ & $0.0 \pm 0.0$ \\
Inf 2 & $84.0 \pm 14.4$ & $36.2 \pm 8.8$ \\
Inf 3 & $112.8 \pm 21.4$ & $49.2 \pm 10.2$ \\
Inf 4 & $128.6 \pm 30.8$ & $67.8 \pm 17.4$ \\
Inf 5 & $147.3 \pm 30.0$ & $68.1 \pm 11.9$ \\
Inf 6 & $159.7 \pm 34.3$ & $75.3 \pm 13.1$ \\
Inf 7 & $177.8 \pm 32.4$ & $81.6 \pm 14.7$ \\
Inf 8 & $199.2 \pm 41.2$ & $80.0 \pm 16.3$ \\
\hline
\end{tabular}

Data given as mean \pm SEM. Preinf, preinfusion day; Inf, infusion day.

droxyprogesterone and $<0.01 \%$ with aldosterone, pregnenolone, estradiol, and progesterone. The inter- and intraassay coefficients of variation were $<10 \%$.

Statistical analysis. Results are presented as means \pm SEM. Blood gas, cardiovascular, and hormone data were analysed using repeated measures ANOVA followed by post hoc Fishers LSD test to determine the difference between the control and FX groups at each time point $(p<0.05)$ (denoted by ${ }^{a}$ when $p$ $<0.05)$ using NCSS Statistical Software (Kaysville, UT. U.S.A.). In addition, the effect of time on changes in measurements from preinfusion day (denoted by ${ }^{\mathrm{b}}$ in the control group and ${ }^{\mathrm{c}}$ in the $\mathrm{FX}$ group) was determined using repeated measures ANOVA followed by post hoc Fishers $t$ tests $(p<0.05)$. Note that the preinfusion and infusion $\mathrm{d} 1$ values are pre-FX exposure. Regression analysis of the relationship between fetal ACTH and cortisol concentrations was accomplished using the least squares method. Animals were excluded from analysis if the fetal cortisol plasma concentration was $>15 \mathrm{nmol} / \mathrm{L}$ on the preinfusion day, as this was an indication that a premature prepartum increase in cortisol may have been present in these animals. One fetus in the FX-treated group died just before the onset of labor. Fetal blood gas and behavioral parameters were in the normal ranges until about $12 \mathrm{~h}$ before death. Accordingly, data from this animal were used only up to infusion d 5. Thus, cortisol and ACTH data were analyzed from eight control and seven FX-treated animals.

\section{RESULTS}

Fetal outcome. On infusion d 8, mean gestational age was $135.4 \pm 0.6 \mathrm{~d}$ in the control group and $135.6 \pm 0.7 \mathrm{~d}$ in the FX group and the number of days before delivery occurred after the end of the infusion period was $7.1 \pm 1.6$ in the control group and $6.3 \pm 1.3$ in the FX group. Birth weight was 3072.8 $\pm 299 \mathrm{~g}$ in the control group and $3645 \pm 252$ in the FX group. There was no significant difference in gestational age, number of days before delivery, or birth weight between the two groups. In the control group, seven of the fetuses were born alive and there were one intrauterine and two intrapartum deaths. In the FX group, four of the fetuses were born alive, but there was one neonatal death. There were also two intrapartum deaths and one death just before the onset of labor.

Maternal and fetal plasma fluoxetine concentration. On infusion d 1, FX levels in both the ewe and fetus peaked $5 \mathrm{~min}$

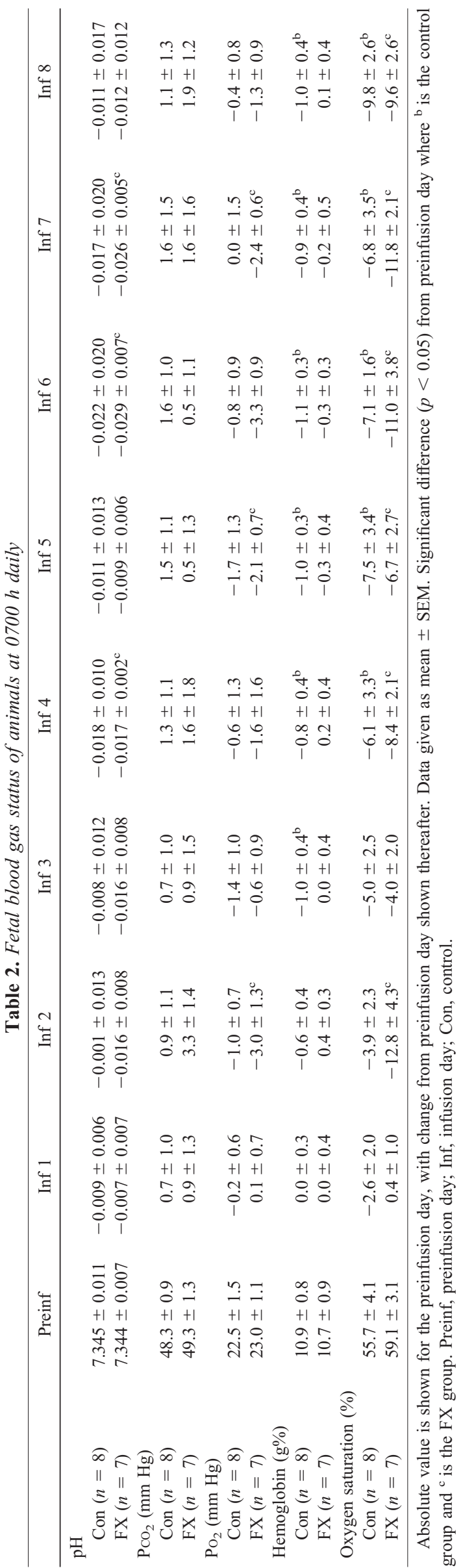


Table 3. Daily average maternal and fetal arterial pressure

\begin{tabular}{|c|c|c|c|c|c|c|c|c|c|}
\hline & Preinf & $\operatorname{Inf} 1$ & $\operatorname{Inf} 2$ & $\operatorname{Inf} 3$ & $\operatorname{Inf} 4$ & $\operatorname{Inf} 5$ & $\operatorname{Inf} 6$ & $\operatorname{Inf} 7$ & $\operatorname{Inf} 8$ \\
\hline Maternal & (mm Hg) & & & & & & & & \\
\hline Con $(n=5)$ & $80.3 \pm 6.9$ & $75.1 \pm 8.2$ & $76.3 \pm 7.8$ & $72.8 \pm 7.9$ & $71.4 \pm 6.8$ & $73.5 \pm 7.4$ & $73.1 \pm 6.1$ & $76.8 \pm 6.8$ & $76.4 \pm 4.2$ \\
\hline $\mathrm{FX}(n=6)$ & $88.4 \pm 6.4$ & $87.4 \pm 6.3$ & $86.1 \pm 5.7$ & $85.6 \pm 5.3$ & $85.3 \pm 5.6$ & $87.5 \pm 6.0$ & $89.0 \pm 7.3$ & $88.4 \pm 6.8$ & $89.5 \pm 9.2$ \\
\hline Con $(n=5)$ & $45.3 \pm 2.1$ & $44.5 \pm 1.8$ & $44.5 \pm 1.4$ & $45.0 \pm 1.8$ & $44.2 \pm 1.4$ & $44.2 \pm 2.5$ & $45.6 \pm 2.0$ & $47.6 \pm 2.7$ & $44.6 \pm 3.4$ \\
\hline $\mathrm{FX}(n=6)$ & $45.1 \pm 1.7$ & $46.8 \pm 0.9$ & $47.1 \pm 1.5$ & $46.1 \pm 1.4$ & $45.8 \pm 1.0$ & $47.3 \pm 0.7$ & $46.2 \pm 1.9$ & $46.2 \pm 0.9$ & $47.1 \pm 1.2$ \\
\hline
\end{tabular}

Data given as mean \pm SEM. No significant differences were observed between the control and FX group or across the experimental period in either group. Preinf, preinfusion day; Inf, infusion day; Con, control.

after the bolus dose and subsequently decreased during the first $6 \mathrm{~h}$ (Table 1). Thereafter, maternal and fetal FX concentrations progressively increased throughout the 8-d infusion, peaking at $199.2 \pm 41.2 \mathrm{ng} / \mathrm{mL}$ in the ewe and at $80.0 \pm 16.3 \mathrm{ng} / \mathrm{mL}$ in the fetus on infusion $\mathrm{d} 8$.

Fetal blood gas status. In the FX group, fetal arterial $\mathrm{PO}_{2}$ was significantly below the preinfusion day value $(23.0 \pm 1.1$ $\mathrm{mm} \mathrm{Hg}$ ) on infusion $\mathrm{d} \mathrm{2,5}$, and $7(p<0.05)$, as indicated in Table 2. Fetal oxygen saturation was also lower $(p<0.05)$ than the preinfusion day value $(59.1 \pm 3.1 \%)$ on infusion $\mathrm{d} 2$, $4,5,6,7$, and 8 in the FX group. A decrease in oxygen saturation $(p<0.05)$ was also observed in the control group on infusion $\mathrm{d} 4,5,6,7$, and 8 compared with the preinfusion day $(55.7 \pm 4.1 \%)$, with the maximum drop of $9.8 \pm 2.6 \%$ on infusion $\mathrm{d} 8$. Fetal $\mathrm{pH}$ was also lower $(p<0.05)$ on infusion $\mathrm{d} 4,6$, and 7 than on the preinfusion day in the FX group. There were no changes in $\mathrm{PCO}_{2}$ in either the control or FX groups; however, $\mathrm{Hb}$ concentrations decreased significantly in the control group on infusion $\mathrm{d} 3,4,5,6,7$, and 8 . No changes in the daily average arterial pressure were observed in the ewes or fetuses within or between the control $(n=5)$ and FX $(n=6)$ groups throughout the experimental period (Table 3).

Plasma ACTH and cortisol concentrations. There was no significant difference in maternal or fetal ACTH between the control and FX groups during the preinfusion period (Fig. 1, $A$ and $B$ ). There was, however, a significant $(p<0.05)$ fall from the preinfusion day in maternal plasma ACTH concentrations in the FX group on infusion $\mathrm{d} 2$ and 3 (Fig. 1A), the maximum fall occurring on infusion d $2(-38.0 \pm 11.9 \mathrm{pg} / \mathrm{mL})$. In contrast, there were no significant changes in maternal ACTH throughout the period of the infusion in the control group. Maternal cortisol concentrations did not change throughout the infusion period in either the FX or control group (Fig. 2A). When ACTH and cortisol concentrations early in the protocol (average concentration on the preinfusion day, infusion $\mathrm{d} 1$ and 2 ) and late in the protocol (average concentration on infusion d 5-8) were pooled, there was a significant increase in maternal cortisol on infusion $\mathrm{d} 5-8$ in the FX group $(46.8 \pm 11.6$ $\mathrm{nmol} / \mathrm{L})$ compared with preinfusion to infusion $\mathrm{d} 2(24.7 \pm 3.4$ $\mathrm{nmol} / \mathrm{L}$ ) in the absence of any change in maternal ACTH.

In the fetus, there was a significant $(p<0.05)$ increase in plasma ACTH concentrations from $37.0 \pm 7.9 \mathrm{pg} / \mathrm{mL}$ on preinfusion day to $75.7 \pm 20.1$ on infusion $\mathrm{d} 7$ in the FX group (Fig. $1 B$ ). There was a significant increase in the fetal plasma cortisol concentrations on infusion d 6,7, and 8 compared with the preinfusion day in both the control and FX groups (Fig. $2 B$ ). The maximum change in fetal cortisol occurred on infu- sion $\mathrm{d} 7$ in both groups, with an increase of $27.0 \pm 15.7 \mathrm{nmol} / \mathrm{L}$ in the control group and $58.5 \pm 16.2 \mathrm{nmol} / \mathrm{L}$ in the FX group. The change in fetal cortisol concentration on infusion $\mathrm{d} 7$ and 8 was significantly greater in the FX group than the control group $(p<0.05)$. In the FX-exposed fetuses, the increase in cortisol [from $34.3 \pm 4.6 \mathrm{nmol} / \mathrm{L}$ (preinfusion to infusion $\mathrm{d} 2$ ) to $87.4 \pm 21.1 \mathrm{nmol} / \mathrm{L}$ (infusion $\mathrm{d} 6-8$ )] was significantly greater when compared with the control group (from $47.0 \pm$ $5.1 \mathrm{nmol} / \mathrm{L}$ to $54.0 \pm 10.2 \mathrm{nmol} / \mathrm{L}$ ). Fetal cortisol concentrations increased in both the control $(29.8 \pm 6.6 \mathrm{nmol} / \mathrm{L})$ and FX $(53.2 \pm 7.4 \mathrm{nmol} / \mathrm{L})$ groups on infusion $\mathrm{d} 5-8$ when compared with preinfusion to infusion d $2(8.7 \pm 1.2 \mathrm{nmol} / \mathrm{L}$, control group; $6.8 \pm 1.0 \mathrm{nmol} / \mathrm{L}$, FX group), and this increase was significantly greater in the FX group $(p<0.05)$.

There was a significant relationship between plasma cortisol (Y) and ACTH (X) concentrations in both the FX and control

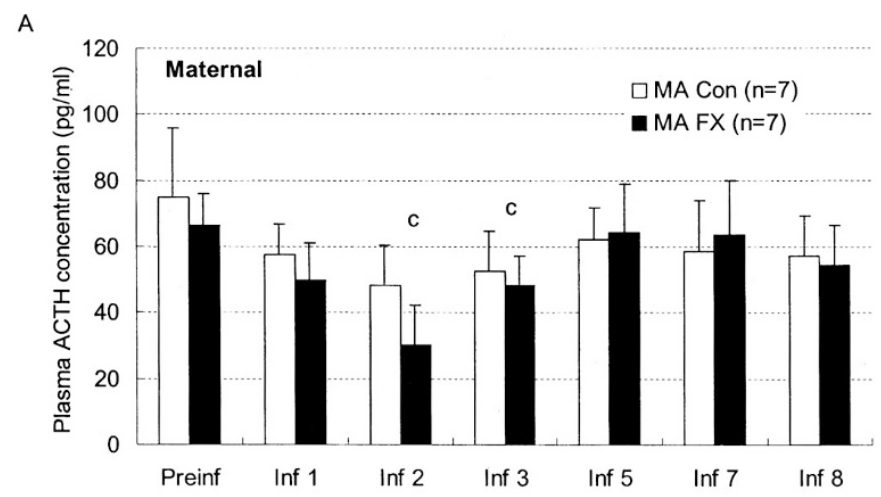

B

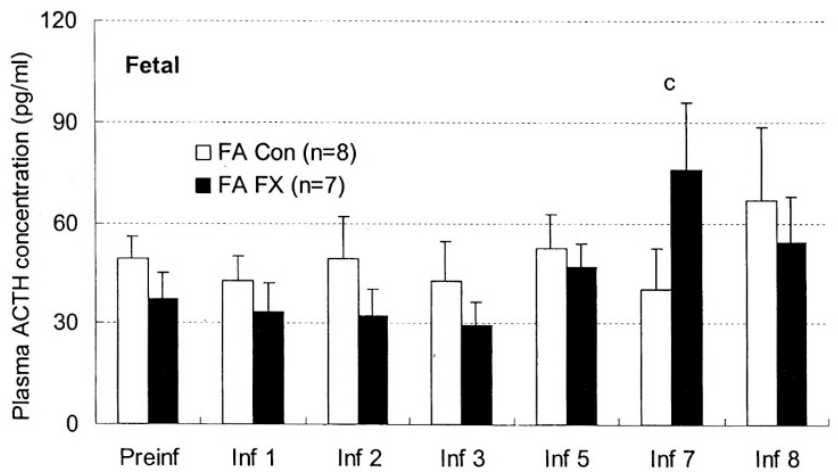

Figure 1. Maternal $(A)$ and fetal $(B)$ arterial plasma ACTH concentrations at $0700 \mathrm{~h}$ on the preinfusion day and $8 \mathrm{~d}$ of sterile water (Con) or FX infusion. ${ }^{\mathrm{c}}$ Significant difference $(p<0.05)$ from preinfusion day FX group. Preinf, preinfusion day; Inf, infusion day; MA, maternal arterial; FA, fetal arterial. 


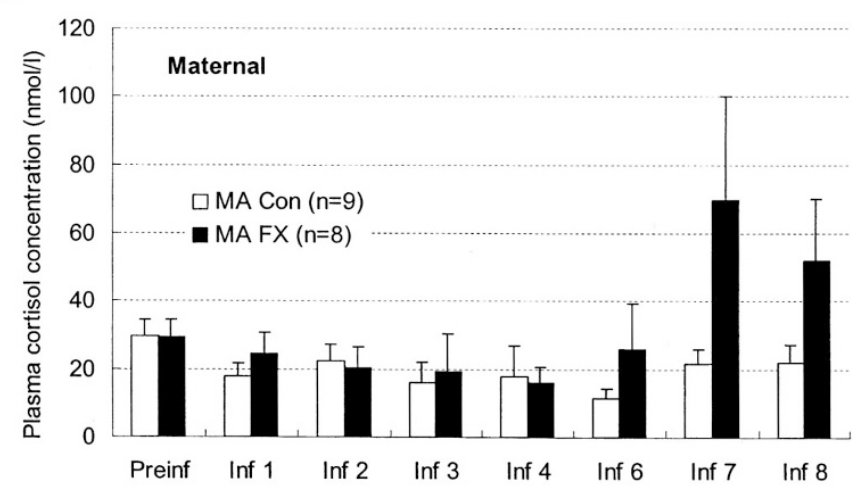

B

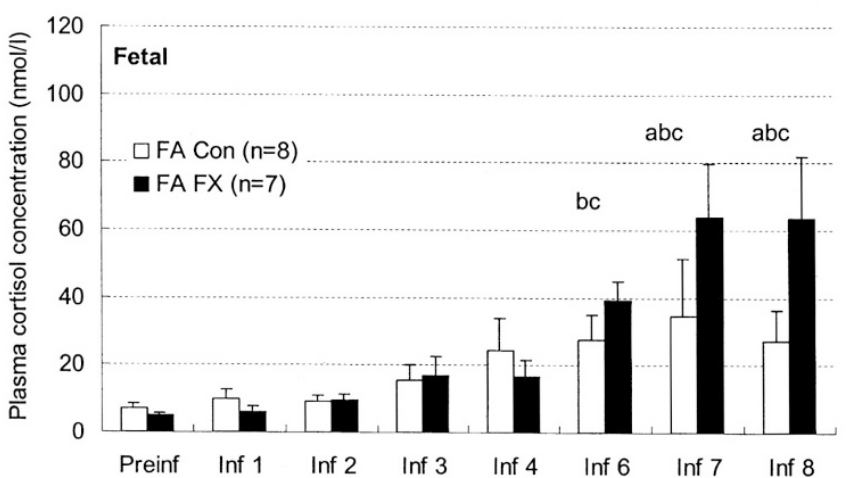

Figure 2. Maternal $(A)$ and fetal $(B)$ arterial plasma cortisol concentrations at $0700 \mathrm{~h}$ on the preinfusion day and $8 \mathrm{~d}$ of sterile water (Con) or FX infusion. ${ }^{a}$ Significant difference $(p<0.05)$ between control and FX groups; significant difference $(p<0.05)$ from preinfusion day in ${ }^{\mathrm{b}}$ control and ${ }^{\mathrm{c}} \mathrm{FX}$ group. Preinf, preinfusion day; Inf, infusion day; MA, maternal arterial; FA, fetal arterial.

groups, as shown in Figure 3. The slope of the relationship, however, was significantly greater $(p=0.02)$ in the FX group than the control group [FX: Y $=0.662 \pm 0.144 * \mathrm{X}-5.03\left(r^{2}\right.$ $=0.3896, p=0.0006, n=35$ ); control: $\mathrm{Y}=0.249 \pm 0.085$ $* \mathrm{X}+3.59(r=0.1703, p=0.005, n=43)]$.

\section{DISCUSSION}

Our results indicate that an 8-d maternal i.v. infusion of FX has little effect on the maternal pituitary-adrenal axis while increasing the magnitude of the normal prepartum rise in fetal plasma cortisol concentration. Although there was a small fall in maternal plasma ACTH on infusion d 2 and 3 in the FX, but not the control group, overall there was no significant effect of FX treatment on maternal plasma cortisol concentration. In contrast, there was a greater rise in fetal plasma ACTH and cortisol in the FX group when compared with the control fetuses.

It has been reported that fetal ACTH plasma levels increase progressively between 110 and $140 \mathrm{~d}$ gestation, whereas fetal cortisol levels remain low between $110-120 \mathrm{~d}$ and increase between 125-140 d gestation (32). McMillen et al. (33) also found that fetal plasma ACTH concentrations double between 120 and $136 \mathrm{~d}$ and 140 and $143 \mathrm{~d}$ gestation. In the current study, fetal plasma ACTH concentrations did not increase in the control group but doubled in the FX group on infusion $\mathrm{d} 7$. One possibility is that FX treatment induced a premature
A

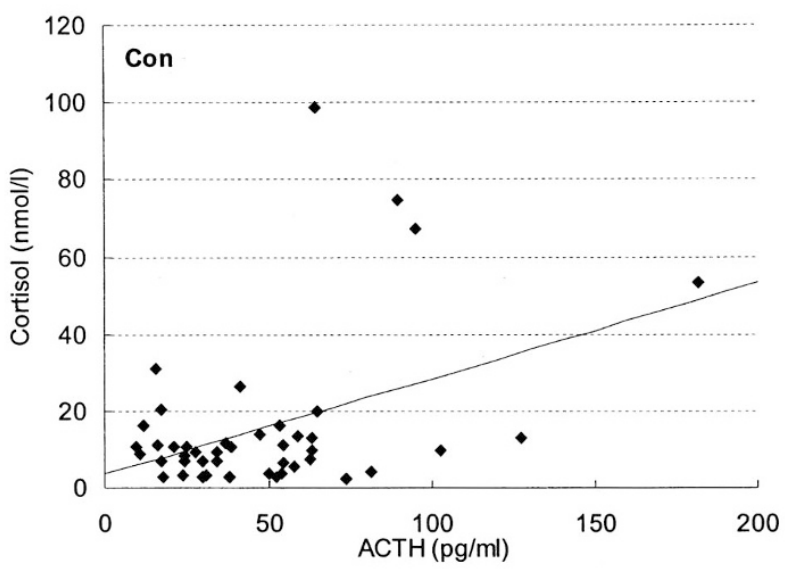

B

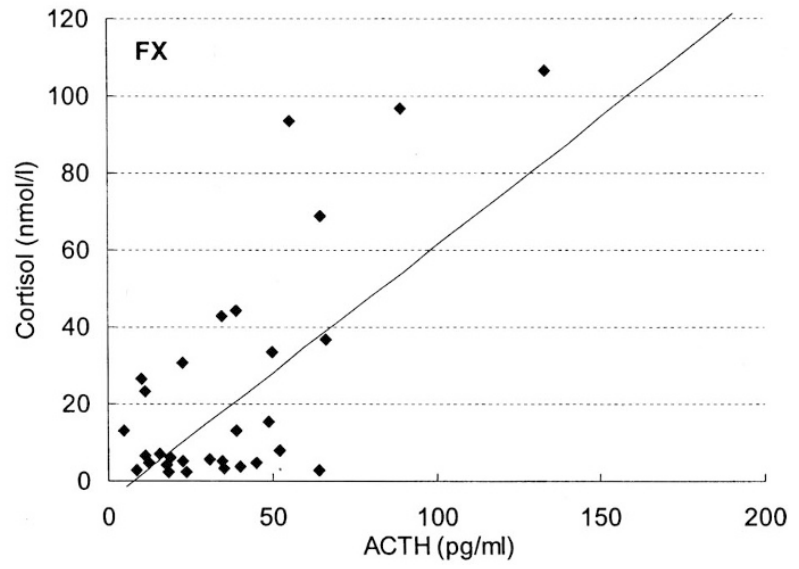

Figure 3. Relationship between fetal plasma ACTH and cortisol concentrations in control $(A)$ and $\mathrm{FX}$-exposed $(B)$ fetuses. The regression equation for the control group is $\mathrm{Y}=0.249 \pm 0.085 * \mathrm{X}+3.59(r=0.1703, p=0.005$, $n=43)$ and for the FX group is $\mathrm{Y}=0.662 \pm 0.144 * \mathrm{X}-5.03\left(r^{2}=0.3896\right.$, $p=0.0006, n=35)$. Con, control group; FX, fluoxetine group.

increase in fetal ACTH at an earlier gestational age (mean $134.5 \pm 1.0 \mathrm{~d}$ ). Alternatively, FX may have acted within the fetal HPA axis either to increase the secretion of the hypothalamic secretagogues, CRH or AVP, or to enhance the sensitivity of the corticotrophs within the fetal pituitary to the actions of CRH or AVP.

Previous studies have reported an increase in plasma cortisol levels in fetal lambs in late gestation, beginning about $9 \mathrm{~d}$ before delivery $(34,35)$. In the current study, this corresponds to infusion d 5 and 4 in control and FX-exposed fetuses, respectively. Thus, the increase in plasma cortisol concentrations between infusion $\mathrm{d} 4$ and 8 in both the control and FX groups is likely to represent the start of the prepartum rise in cortisol. In the present study, we found that the increase in fetal cortisol was greater in the FX-treated group on infusion d 5-8, and that plasma cortisol concentrations appeared to be higher in this group at any given ACTH concentration. This suggests that the fetal adrenal sensitivity to ACTH may have increased in the FX group (36). It is possible that FX treatment resulted in a stimulation of the secretion of proopiomelanocortin (POMC) products other than ACTH from the fetal pituitary. It has been shown that N-POMC 1-77 has a stimulatory action on fetal adrenal growth and steroidogenic enzyme expression 
during late gestation (34). An alternative possibility is that FX acted in the fetal CNS to increase stimulation of the fetal adrenal by the cholinergic preganglionic splanchnic nerve. It has been demonstrated that the splanchnic nerve plays a role in the modulation of the adrenal responsiveness to ACTH stimulation (37).

Acute hypoxemia and acidemia are potent stimuli for ACTH and cortisol release in the fetus $(31,38-44)$. Although there were small decreases in fetal arterial $\mathrm{Po}_{2}$ in the $\mathrm{FX}$ groups during the infusion period, the fetal arterial $\mathrm{Po}_{2}$ values did not fall below levels associated with a pituitary-adrenal response to fetal hypoxemia in either acute or chronic studies $(39,40)$. It is therefore unlikely that the changes in fetal blood gas status contributed to the fetal pituitary-adrenal response to maternal FX infusion.

It has previously been shown that cortisol plays a role in the regulation of fetal blood pressure. An intrafetal infusion of cortisol for $24 \mathrm{~h}$ during the period between 103 and $120 \mathrm{~d}$ gestation resulted in an increase in fetal plasma cortisol concentrations to levels similar to those observed close to term and a concomitant increase in blood pressure (45). Although changes in fetal blood pressure and heart rate were observed in the first $24 \mathrm{~h}$ after FX infusion (12), these changes are not associated with changes in fetal cortisol concentrations and there were no changes in either maternal or fetal blood pressure and heart rate during the 8-d FX infusion period. Although infusion of cortisol between 103 and $120 \mathrm{~d}$ gestation resulted in an increase in fetal blood pressure, infusion of cortisol for a 24-h period between 130 and $137 \mathrm{~d}$ did not result in any change in fetal arterial blood pressure, and it is likely that further elevations of fetal cortisol above those levels normally present during the prepartum period will not result in further elevations in fetal blood pressure (45).

Maternal FX plasma concentrations rose on each day of the experiment, but were within the human therapeutic range of $35-415 \mathrm{ng} / \mathrm{mL}(12,46)$. Changes in fetal plasma ACTH and cortisol concentrations were not observed during the first $5 \mathrm{~d}$ of FX treatment despite high plasma FX concentrations. This may be related to serotonin receptor function. One of the effects of the rise in extracellular serotonin elicited by FX and other SSRIs is to down-regulate the $5-\mathrm{HT}_{1 \mathrm{~A}}$ autoreceptors that inhibit the firing of serotonergic neurons in the raphe nucleus. However, in adults, this appears to require $2-3$ wk of FX treatment (47). In the fetus, the development of the brain serotonin system begins early in gestation, with serotonin immunoreactive perikarya present in the $110 \mathrm{~d}$ gestation sheep fetus with well-developed neuritic processes (48). During development, serotonin receptors may be more susceptible to down-regulation than in the adult. In rats, increased serotonin concentrations during pregnancy induced through a tryptophan-enriched diet or through 5-methoxytryptophan treatment delays serotonin axon outgrowth and/or decreases collateral sprouting, synapse formation, and induces receptor downregulation $(49,50)$. Pharmacodynamic modelling was performed to determine whether there was a relationship between maternal or fetal FX concentrations and ACTH or cortisol concentrations but no correlations were found (data not shown).
Our data show that maternal FX administration increases fetal plasma cortisol concentration during late gestation. Previously we have reported that maternal FX infusion reduces the incidence of low-voltage/rapid eye movement (LV/REM) behavioral state in the fetal lamb, and that this effect persists for the entire 8-d infusion period (29). Thus, FX exposure alters the level of activation of both the HPA axis and fetal behavior (13) and these alterations could underlie some of the postnatal consequences observed in human infants exposed prenatally to SSRIs (7, 9-11). What is not yet clear is whether the FXelicited alterations in the fetal HPA axis persist beyond the period of drug exposure and into the postnatal period. Study of postnatal HPA function after in utero SSRI exposure is required to substantiate this possibility. It has been shown in experimental animal studies that exposure to synthetic glucocorticoids during late gestation results in a subsequent increase in blood pressure, in the hepatic production of glucose and in basal cortisol concentrations in adult life (51). Thus exposure to excess glucocorticoids in utero as a consequence of exposure of the fetus to therapeutic agents such as the synthetic glucocorticoids used in the treatment of threatened preterm labor (52) or the SSRIs may have consequences for fetal and postnatal health.

Acknowledgment. The authors thank Anne Jurisevic for her expert research assistance.

\section{REFERENCES}

1. Weissman MM, Olfson M 1995 Depression in women: implications for health care research. Science 269:799-801

2. Steer RA, Scholl TO, Hediger ML, Fischer RL 1992 Self-reported depression and negative pregnancy outcomes. J Clin Epidemiol 45:1093-1099

3. Stahl SM 1998 Basic psychopharmacology of antidepressants, part 1: antidepressants have seven distinct mechanisms of action. J Clin Psychiatry 59:5-14

4. Nonacs R, Cohen LS 2002 Depression during pregnancy: diagnosis and treatment options. J Clin Psychiatry 63:24-30

5. Simon GE, Cunningham ML, Davis RL 2002 Outcomes of prenatal antidepressant exposure. Am J Psychiatry 159:2055-2061

6. Chambers CD, Johnson KA, Dick LM, Felix RJ, Jones KL 1996 Birth outcomes in pregnant women taking fluoxetine. N Engl J Med 335:1010-1015

7. Laine K, Heikkinen T, Ekblad U, Kero P 2003 Effects of exposure to selective serotonin reuptake inhibitors during pregnancy on serotonergic symptoms in newborns and cord blood monoamine and prolactin concentrations. Arch Gen Psychiatry 60:720-726

8. Hendrick V, Smith LM, Suri R, Hwang S, Haynes D, Altshuler L 2003 Birth outcomes after prenatal exposure to antidepressant medication. Am J Obstet Gynecol 188:812-815

9. Chambers CD, Anderson PO, Thomas RG, Dick LM, Felix RJ, Johnson KA, Jones KL 1999 Weight gain in infants breastfed by mothers who take fluoxetine. Pediatrics 104:E61

10. Casper RC, Fleisher BE, Lee-Ancajas JC, Gilles A, Gaylor E, DeBattista A, Hoyme HE 2003 Follow-up of children of depressed mothers exposed or not exposed to antidepressant drugs during pregnancy. J Pediatr 142:402-408

11. Oberlander TF, Eckstein Grunau R, Fitzgerald C, Ellwood AL, Misri S, Rurak D, Riggs KW 2002 Prolonged prenatal psychotropic medication exposure alters neonatal acute pain response. Pediatr Res 51:443-453

12. Morrison JL, Chien C, Riggs KW, Gruber N, Rurak D 2002 Effect of maternal fluoxetine administration on uterine blood flow, fetal blood gas status, and growth. Pediatr Res 51:433-442

13. Delarue C, Contesse V, Lenglet S, Sicard F, Perraudin V, Lefebvre H, Kodjo M, Leboulenger F, Yon L, Gallo-Payer N, Vaudry H 2001 Role of neurotransmitters and neuropeptides in the regulation of the adrenal cortex. Rev Endocr Metab Disord 2:253-267

14. Carrasco GA, Van de Kar LD 2003 Neuroendocrine pharmacology of stress. Eur J Pharmacol 463:235-272

15. Fuller RW 1996 Serotonin receptors involved in regulation of pituitary-adrenocortical function in rats. Behav Brain Res 73:215-219

16. Kageyama K, Tozawa F, Horiba N, Watanobe H, Suda T 1998 Serotonin stimulates corticotropin-releasing factor gene expression in the hypothalamic paraventricular nucleus of conscious rats. Neurosci Lett 243:17-20 
17. Bagdy G 1996 Role of the hypothalamic paraventricular nucleus in 5-HT1A, 5-HT2A and 5-HT2C receptor-mediated oxytocin, prolactin and $\mathrm{ACTH} /$ corticosterone responses. Behav Brain Res 73:277-280

18. Berlin I, Warot D, Legout V, Guillemant S, Schollnhammer G, Puech AJ 1998 Blunted 5-HT1A-receptor agonist-induced corticotropin and cortisol responses after long-term ipsapirone and fluoxetine administration to healthy subjects. Clin Pharmacol Ther 63:428-436

19. Lerer B, Gelfin Y, Gorfine M, Allolio B, Lesch KP, Newman ME 1999 5-HT1A receptor function in normal subjects on clinical doses of fluoxetine: blunted temperature and hormone responses to ipsapirone challenge. Neuropsychopharmacology 20:628-639

20. Raap DK, Evans S, Garcia F, Li Q, Muma NA, Wolf WA, Battaglia G, Van De Kar LD 1999 Daily injections of fluoxetine induce dose-dependent desensitization of hypothalamic 5-HT1A receptors: reductions in neuroendocrine responses to 8-OHDPAT and in levels of Gz and Gi proteins. J Pharmacol Exp Ther 288:98-106

21. Li Q, Levy AD, Cabrera TM, Brownfield MS, Battaglia G, Van de Kar LD 1993 Long-term fluoxetine, but not desipramine, inhibits the ACTH and oxytocin responses to the 5-HT1A agonist, 8-OH-DPAT, in male rats. Brain Res 630:148-156

22. Li Q, Brownfield MS, Levy AD, Battaglia G, Cabrera TM, Van de Kar LD 1994 Attenuation of hormone responses to the 5-HT1A agonist ipsapirone by long-term treatment with fluoxetine, but not desipramine, in male rats. Biol Psychiatry 36:300-308

23. Pohland RC, Byrd TK, Hamilton M, Koons JR 1989 Placental transfer and fetal distribution of fluoxetine in the rat. Toxicol Appl Pharmacol 98:198-205

24. Kim J 2000 Pharmacokinetics and pharmacodynamics of the selective serotonin reuptakes inhibitors, fluoxetine and paroxetine, during pregnancy and the nursing period. Faculty of Pharmaceutical Sciences, University of British Columbia, Vancouver

25. Kim J, Riggs KW, Rurak DW 2004 Stereoselective pharmacokinetics of fluoxetine and norfluoxetine enantiomers in pregnant sheep. Drug Metab Disp 32:212-22

26. Chien C 2003 Chronic exposure and pharmacokinetics of fluoxetine and norfluoxetine enantiomers in the pregnant ewe and fetus. Faculty of Pharmaceutical Sciences, University of British Columbia, Vancouver

27. Richards GE, Kendal JZ 1987 Effect of intravenous 5-hydroxytryptophan on hypothalamic concentration of norepinephrine, dopamine, serotonin and hydroxyindole acetic acid in the fetal lamb. Life Sci 40:2001-2005

28. Rurak DW, Yoo SD, Kwan E, Taylor SM, Riggs KW, Axelson JE 1988 Effects of diphenhydramine in the fetal lamb after maternal or fetal administration. J Pharmacol Exp Ther 247:271-278

29. Morrison JL, Chien C, Gruber N, Rurak D, Riggs W 2001 Fetal behavioural state changes following maternal fluoxetine infusion in sheep. Brain Res Dev Brain Res $131: 47-56$

30. Adams MB, Ross JT, Butler TG, McMillen IC 1999 Glucocorticoids decrease phenylethanolamine N-methyltransferase mRNA expression in the immature foetal sheep adrenal. J Neuroendocrinol 11:569-575

31. Bocking AD, McMillen IC, Harding R, Thorburn GD 1986 Effect of reduced uterine blood flow on fetal and maternal cortisol. J Dev Physiol 8:237-245

32. Norman LJ, Lye SJ, Wlodek ME, Challis JR 1985 Changes in pituitary responses to synthetic ovine corticotrophin releasing factor in fetal sheep. Can J Physiol Pharmacol 63:1398-1403

33. McMillen IC, Phillips ID, Ross JT, Robinson JS, Owens JA 1995 Chronic stress - the key to parturition? Reprod Fertil Dev 7:499-507

34. Kitts DD, Anderson GB, BonDurant RH, Stabenfeldt GH 1984 Temporal patterns of delta 4 C-21 steroids in coexisting, genetically dissimilar twin lamb fetuses throughout late gestation. Endocrinology 114:703-711
35. Magyar DM, Fridshal D, Elsner CW, Glatz T, Eliot J, Klein AH, Lowe KC, Buster JE, Nathanielsz PW 1980 Time-trend analysis of plasma cortisol concentrations in the fetal sheep in relation to parturition. Endocrinology 107:155-159

36. Brooks AN, Challis JR, Norman LJ 1987 Pituitary and adrenal responses to pulsatile ovine corticotropin-releasing factor administered to fetal sheep. Endocrinology 120:2383-2388

37. Myers DA, Robertshaw D, Nathanielsz PW 1990 Effect of bilateral splanchnic nerve section on adrenal function in the ovine fetus. Endocrinology 127:2328-2335

38. Boddy K, Dawes GS, Fisher R, Pinter S, Robinson JS 1974 Foetal respiratory movements, electrocortical and cardiovascular responses to hypoxaemia and hypercapnia in sheep. J Physiol 243:599-618

39. Towell ME, Figueroa J, Markowitz S, Elias B, Nathanielsz P 1987 The effect of mild hypoxemia maintained for twenty-four hours on maternal and fetal glucose, lactate, cortisol, and arginine vasopressin in pregnant sheep at 122 to 139 days' gestation. Am J Obstet Gynecol 157:1550-1557

40. Akagi K, Challis JR 1990 Threshold of hormonal and biophysical responses to acute hypoxemia in fetal sheep at different gestational ages. Can J Physiol Pharmacol 68:549-555

41. Challis JR, Richardson BS, Rurak D, Wlodek ME, Patrick JE 1986 Plasma adrenocorticotropic hormone and cortisol and adrenal blood flow during sustained hypoxemia in fetal sheep. Am J Obstet Gynecol 155:1332-1336

42. Hooper SB, Coulter CL, Deayton JM, Harding R, Thorburn GD 1990 Fetal endocrine responses to prolonged hypoxemia in sheep. Am J Physiol 259:R703-R708

43. Murotsuki J, Gagnon R, Matthews SG, Challis JR 1996 Effects of long-term hypoxemia on pituitary-adrenal function in fetal sheep. Am J Physiol 271:E678-E685

44. Gagnon R, Lamb T, Richardson B 1997 Cerebral circulatory responses of near-term ovine fetuses during sustained fetal placental embolization. Am J Physiol 273:H2001-H2008

45. Tangalakis K, Lumbers ER, Moritz KM, Towstoless MK, Wintour EM 1992 Effect of cortisol on blood pressure and vascular reactivity in the ovine fetus. Exp Physiol 77:709-717

46. Benfield P, Heel RC, Lewis SP 1986 Fluoxetine. A review of its pharmacodynamic and pharmacokinetic properties, and therapeutic efficacy in depressive illness. Drugs 32:481-508

47. Lanfumey L, Hamon M 2000 Central 5-HT(1A) receptors: regional distribution and functional characteristics. Nucl Med Biol 27:429-435

48. Tillet Y 1988 Early ontogeny of serotonin-immunoreactivity in the sheep brain. An immunohistochemical study. Anat Embryol (Berl) 178:429-440

49. Huether G, Thomke F, Adler L 1992 Administration of tryptophan-enriched diets to pregnant rats retards the development of the serotonergic system in their offspring. Brain Res Dev Brain Res 68:175-181

50. Whitaker-Azmitia PM, Lauder JM, Shemmer A, Azmitia EC 1987 Postnatal changes in serotonin receptors following prenatal alterations in serotonin levels: further evidence for functional fetal serotonin receptors. Brain Res 430:285-289

51. Levitt NS, Lindsay RS, Holmes MC, Seckl JR 1996 Dexamethasone in the last week of pregnancy attenuates hippocampal glucocorticoid receptor gene expression and elevates blood pressure in the adult offspring in the rat. Neuroendocrinology 64:412418

52. Newnham JP, Moss TJ, Nitsos I, Sloboda DM 2002 Antenatal corticosteroids: the good, the bad and the unknown. Curr Opin Obstet Gynecol 14:607-612 